\title{
Maternity and paternity leave and career progression of black African women in dual-career couples
}

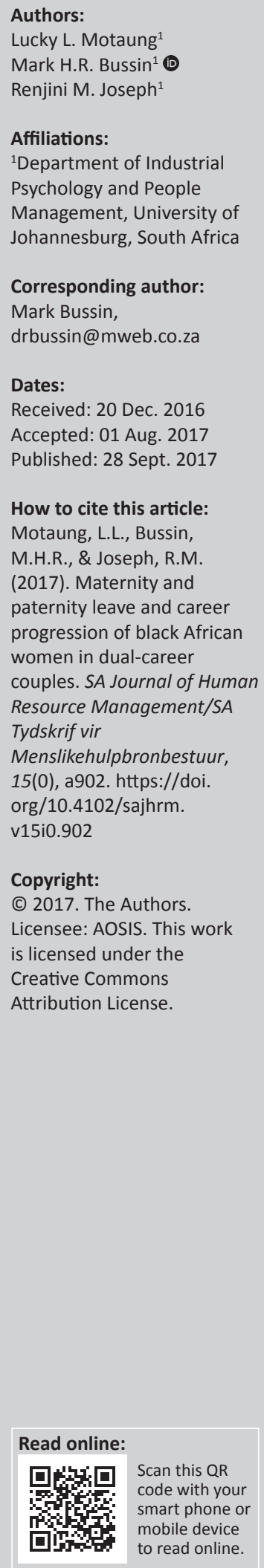

Orientation: The study focused on examining the perceptions of dual-career couples at a stateowned company about the influence of taking maternity and paternity leave on the career progression of black African women in middle management and leadership occupations.

Research purpose: The primary purpose of the study was to identify core barriers in relation to maternity and paternity leave that contribute negatively in the career progression of black African women in dual-career couples.

Motivation for the study: To obtain insight into the underrepresentation and progression of black African women within dual-career couples, in middle management and leadership occupations.

Research design, approach and method: This study was qualitative, comprising a sample of 10 black African women and 10 black African men, with data collected through in-depth semistructured interviews. Thematic analysis was utilised to analyse the interview dialogues.

Main findings: The findings established that taking maternity leave has a negative influence on the career progression of black African women in dual-career couples at the state-owned company. The participants further confirmed that involuntary time off work and productiveness were principal influencing barriers of taking maternity leave, leading to other undesirable consequences, such as unproductiveness and reliability.

Practical and managerial implications: The state-owned company should review its current talent management and recruitment and selection policies, in order to positively contribute to increasing the representation and facilitating career progression of black African women within dual-career couples, in middle management and leadership occupations.

Contributions or value-add: Insights were provided on the influences of taking maternity and paternity leave in the underrepresentation and progression of black African women within dual-career couples, in middle management and leadership occupations.

\section{Introduction}

Family and organisational support are two primary elements that play a pivotal role in the career progression of women into leadership and top management roles, especially those who are part of a dual-career couple (DCC) (Smit, 2006). Many current work practices do not facilitate gender equality (Smit, 2006), which is one of the values upheld by the South African Constitution and the Employment Equity Act (Labour Relations Act, RSA, 1998b; RSA Constitution, 1996). In relation to this article, there exists a challenge in the underrepresentation of black African women in middle management and leadership occupations, as well as their slow progression to such positions.

\section{Focus of the study}

The study focused on examining how taking maternity leave (ML) and paternity leave (PL) influences the career progression of black African women in DCCs, in middle management and leadership occupations. The study was conducted in a state-owned company (SOC), as SOCs are some of the primary custodians in promoting equal employment opportunities as per the Employment Equity Act (EEA, 1998a). SOCs are legal entities that undertake commercial activities on behalf of an owner government. The legal status of an SOC varies from being part of the government to being stock companies with the state as a majority stakeholder (Public Finance Management Act 1, 1999).

The primary purpose of the study was to identify core barriers in relation to ML and PL that contribute negatively to the career progression of black African women in DCCs. The study also 
enabled the researcher to determine how black African women manage tension between their work and family roles and the impact this may have on their career goals and success. It could be argued that if a woman successfully manages family responsibilities with sufficient and relevant support, her career could positively progress, as she will have a fair opportunity to pursue her career goals (Nath, 2000). The study provided a broad examination of how taking ML and PL may influence the career progression of black African women as part of a DCC in middle management and leadership occupations at an SOC, by examining both internal and external factors.

\section{Background to the study}

For the purposes of this study, the term black African women refers to only black South African women, excluding women of mixed race and those of Indian background. The below extract provides an indication on how black African women are bound, to a certain extent, by culturally inherent practices that define them, and their place in society and within the family unit:

The vital life goal of Black African women is to be oriented within their culture. This means to be rooted in the knowledge and practice of the culture of one's peoples, to extract lessons from it and to use it in emancipatory, transformative and enriching ways. Being a Black African women begins with and is rooted in African tradition and culture. (Karenga \& Tembo, 2012, p. 40)

Traditionally, men were expected to fulfil the role of sole earner in the household. Women were then expected to assume economic dependency and the role of motherhood, with no aspiration for career acknowledgement and fulfilment (Bosch, De Bruin, De Bruin \& Kgaladi, 2012). Bosch et al. (2012) also indicated that, from an early age, black African girls are culturally indoctrinated to grow up into childbearing and motherhood roles, whereby they do not see themselves as equal to men in any aspects of their being.

Such socialisation can bring about many consequences that could eventually influence young black African women when they are mature and are required to make life-enhancing decisions that affect their future and growth. Such influence could bring about thinking among black African women that they would never be equal to men, be it socially or economically. For many years, the majority of black African women have been inactive in the employment arena, with most of those that are employed not being as career-orientated as men. This is a result of the historical role that was imposed on them (Greenhaus, Callanan \& Godshalk, 2010). Although more black African women are now employed, there exist some consequences of the socialisation of black African women.

Herman (2016) and Mumma (2001) describe a DCC as a household where both the woman and the man earn an income and both spouses are dedicated to their professional occupations in which they pose specialist content knowledge in their field. Being a spouse in a DCC can be a challenging role, which entails time and devotion (Greenhaus \& Powell, 2006; IIies, Keeney \& Scott, 2011).

Hall (2002) defined a career as a lifetime development of employment-related engagements and deeds that embrace both objective and independent elements. Career success may have different meanings for men and women from the beginning of their careers to maturity. Rajadhyaksha and Bhatnagar (2000) argued that the significant difference between the male and female definitions of career success is that women aspire to achieve importance in what they deliver, when compared to men, who aspire for seniority in their occupations.

\section{Research objective and problem}

The primary aim of the study was to examine how taking ML and PL influences the career progression of black African women as part of DCCs at an SOC. The research problem was that we did not adequately understand the impact that taking ML and PL had on the career progression of black African women as part of DCCs at the SOC, within middle management and leadership occupations.

\section{Trends from literature}

Motherhood has developed from the standard care-giving role towards a role of rising importance regarding attaining individual aspirations within the context of life, as well as a career (Moore, 2013). The current minimal participation of men as caregivers in the form of formalised PL puts more pressure on women in balancing their careers and care-giving roles (Moore, 2013).

The fertility rate of black African women in 2010, with an average of 2.3 children, shows a clear obligation that is still being experienced by black African women in their quest to balance career goals and childbearing responsibilities (Smit, 2006). The fertility rate of black African women dropped from 6.8 in the 1950s, to 5.8 in the 1970s, to the current rate of 2.3, which suggests that black African women are now minimising and delaying childbearing in an attempt to focus more on their career goals and progress and to minimise their time off work because of ML (Moore, 2013). Among other reasons, this delay could also be because of financial constraints resulting from the high unemployment rate among black African women (Stats SA, 2015). Nonetheless, it is imperative to take note that having children, although fewer than before, is still a vital part of black African women's identity, even though it may influence their career progression and success (Moore, 2013).

While care-giving behaviours have been mostly related to feminine values and characteristics (Mainiero \& Sullivan, 2005), recent studies indicate that, to a large extent, men are also developing increased self-consciousness regarding care roles (Harrington, Van Deusen \& Mazar, 2012). Men not only aspire to be economically supportive but also seek to be 
psychologically and physically supportive within their households (Harrington et al., 2012). In Ireland, where PL is policy, working fathers who have utilised PL mentioned that it has enabled them to be good fathers to their children and to feel more psychologically attached to their family units (Pesonen, 2015). This indicates the essential support PL can provide to the DCC family unit and broader socio-economic context if properly and legislatively formalised.

\section{Value-add of the study}

Through this study, it has been established that taking ML and PL has a direct and indirect influence on the perceived career progression of black African women in DCCs at a specific SOC, in middle management and leadership occupations. In the acknowledgement of this influence, the study also contributed to the limited theory and knowledge on the topic and field of study within the context of South Africa (SA). Furthermore, the study identified a relationship between the black African women and black African men in their experiences and understandings of the influence of ML on the career progression of black African women in DCCs at an SOC, with a $90 \%$ support of such an influence across all the participants. The identification of this relation proved to be quite essential and added value to the overall study in indicating certain commonalities regarding how black African women and black African men perceive one another within the workplace and family environment.

The following section reviews relevant current literature on ML and PL and the career progression of black African women. The research design is then presented followed by a report on the data gathered. The article is concluded after a detailed discussion on the main findings, limitations of the study and recommendations for future research.

\section{Literature review}

\section{Black African women in the South African labour market}

The isolation of women in the notion of working-class encounters in SA must ideally be studied within the framework of the colonial and apartheid constructions of African women (Tshoaedi, 2012). Overall, women in the SA labour market have been secluded and discriminated against for a number of years, whereby for a majority of them, their contributions, if any, were only restricted to unskilled roles (Floro \& Komatsu, 2011; Gurjao, 2006). Despite the effects of colonialism and apartheid, numerous positive strides have been made in the liberation and upliftment of women and black African women in the SA labour market (EEA, 1998a).

Some of these developments lie in the establishment of legislation and policies that promote the participation of women in the labour market, such as the LRA of 1995, the EEA, the Skills Development Act of 1998. These legislative policies have played a great role in promoting the equality journey of women in the SA labour market (EEA, 1998a).
In spite of some of the accomplishments of women in SA, a lot still has to be overcome both socially and economically to see more meaningful change for women in SA. It has been argued that notwithstanding the nuanced gender equality rights and complemented legislation on paper, women still encompass the majority of the underprivileged and marginalised in SA (Sadie, 2015). This marginalisation transpires in that 'patriarchal' power still underlies the economic relegation of women (Bentley, 2004). The overarching dilemma in this negative phenomenon is that some of these equality policies tend to only look promising on paper, but most of the time their practical implementation lacks impact (Sadie, 2015). It can be argued that out of all the races of women in SA, black African women have been by far the worst affected and discriminated against in many possible ways (Flood, Hoosain \& Primo, 1997).

Historically, black African women who were privileged enough to have been employed were customarily employed as domestic workers mainly. In 1998, an estimated total average of more than $80 \%$ of all domestic workers was black African women. While also concurrently acting as heads of their families in certain instances, black African women were greatly disadvantaged, as they also often received far lower incomes than black African men (Forger et al., 2001; Ministry for Welfare \& Population Development, 1998).

During black African women's career progression prior to 1994, black African women were subjected to a conceptual acknowledgement called 'double jeopardy' or 'double discrimination' (De Vries, 1991; Davidson, 1997; Sewpaul, 1994; Talley-Poss, 1995). Black African women in SA were being oppressed, both for being 'black' and also for being women (Commission of Gender Equality, 2001). These were some of the unfortunate realities that black African women were faced with in their daily lives within the SA labour market and broader socio-economic landscape, in addition to their struggle for equality and liberation. There may be undesirable effects of such 'double discrimination' that could have hindered their confidence, self-esteem and courage. It can be contended that these effects may still be indoctrinated in some of their social behaviours, which could take years to totally eradicate within their psychological system and general outlook on life.

\section{Attainments and challenges in maternity leave}

Maternity leave refers to granting women time off work before and after childbirth and, in some cases, for adoption of a child (Basic Conditions of Employment Act [BCEA], 1997; Smit, 2006). This time off provides some degree of job and social security to women during the process of childbirth and early childcare (BCEA, 1997).

In the SA context, ML is a legislative entitlement under the BCEA, which stipulates that ML can be taken for a period of up to four consecutive months (BCEA, 1997). Employers have their own policies on remunerating employees, but if an employer does not provide financial ML benefits, a female 
employee can claim benefits for 17 weeks from the Unemployment Insurance Fund (UIF). Givati and Troiano (2012) argue that the provision of paid ML is an inadequate answer to the numerous impediments of maternity discrimination, disparity in the workplace and lack of representation of women in managerial and leadership occupations. Paid ML may be regarded as only a small advance in the journey towards eradicating all forms of discrimination against women in our labour markets.

It is also quite cognisant to appreciate the efforts by some countries including SA and many European countries in making paid ML a reality, whereas women in other countries like United States are not privileged to this right (LRA, 1995; OECD, 1995). Contemporary research has revealed that the main impact of paid ML could merely just be a gesture to the acknowledgement of equality and inclusion, supplementary to it being a definite diagnosis for it (Givati \& Troiano, 2012).

\section{Attainments and challenges in paternity leave}

Paternity leave refers to the short-term leave available to fathers in the period subsequent to the delivery or adoption of a child, affording men the opportunity to devote additional time to their families, while maintaining job security (Evans, 2007; Haas, 2003). It is important to acknowledge that PL is not legally enforced within the SA labour environment and that it is only utilised as a benefit within the family responsibility leave category for fathers, limited only to 3 days per annum in some organisations (BCEA, 1997; Mokomane, 2009; Morrell \& Richter, 2006).

Most southern African countries compare poorly to European Union countries when comparing PL policies and legislation. Slovenia offers PL of 90 days, Finland 7-21 days and Denmark 14 days (Lammi-Taskula, 2008; quoted in Smit, 2006). Moss (2012) highlights PL as a compensated father's privilege as opposed to a duty, to a few days absence, engaged concurrently with the mother after childbirth. As much as PL may be an entitlement, it is important to take cognisance that PL is not considered a right to men, but only a privileged entitlement to a few (Mokomane, 2009; Morrell \& Richter, 2006).

There is little knowledge documented regarding the understanding and involvement of black African men as fathers within the context of PL (Wall, 2014). The uniqueness regarding black African men is to be seen in their embedded culture and traditional conceptions in terms of a woman's role in the family unit as 'housewife and child bearer' (Santho, 1995). It is also important to acknowledge that this cultural stigma is slowly fading away among black African men who are fathers, as many men seem to appreciate the value of PL recently (Wall, 2014).

\section{Motherhood and marriage within the labour markets}

Hardill (2002) mentions that although there is autonomous decision making regarding compensated employment, the obligations of social reproduction still exclusively remain a women's responsibility. This highlights the overencompassing challenge of women having to maintain a peculiar balance between their ever-conflicting roles, as childbearer and as full-time employee (Atkinson \& Hall, 2009). Empirical evidence indicates that, even within DCC households, gender disparities in decision making and time allocation still remains an incitement, with some degree of disagreement and compromise extremely persistent (Wheatly, 2013).

The interchange to parenthood may seem to be a seamless family portrayal, but may also have the potential of negatively impacting the work domain (Wheatly, 2013). Salmera-Aro, Nurmi, Saisto and Halmesmaki (2000) argue in congruence of this imbalanced development in a study of pregnant parents. The study indicated that the conversion to parenthood not only affects individual goals in the domestic domain but also hinders achievement objectives within the employment domain as well. They further indicated that during pregnancy, women tend to prioritise family-associated objectives more and employment achievement aspirations less, whereas there was no subsequent impact on the employment achievement goals among men (Salmera-Aro et al., 2000).

\section{Representation of black African women in management positions and their progression to leadership roles in the South African labour market}

Table 1 indicates the high labour force population of black African women within the SA labour market across all groups of women. Even though black African women represent the majority of women within the labour market at $73.5 \%$ in 2015 , it must be noted that most of them only occupy semiskilled to low-skilled jobs. Out of their overall 73.5\% labour force composition, $39.0 \%$ occupy semi-skilled occupations and $43.4 \%$ occupy low-skilled occupations, leaving only $17.6 \%$ occupying skilled jobs within which middle management and leadership roles would fall.

Table 1 further highlights that white and Indian/Asian women workforce groups dominate employment in skilled occupations as compared to black African women and women of mixed race, despite black African women being the dominant group within the woman workforce. Black African women remain highly underrepresented and disadvantaged within skilled, professional and managerial occupations at only $17.6 \%$ - the lowest of all the women groups. This negative gap that exists to date between black

TABLE 1: Employment by occupation, population group and sex, Q3: 2015.

\begin{tabular}{lccc}
\hline Women & Skilled & Semi-skilled & Low-skilled \\
\hline White & 57.8 & 41.4 & 0.8 \\
Asian/Indian & 48.0 & 47.9 & 4.1 \\
Mixed race & 20.7 & 46.6 & 32.7 \\
Black African & 17.6 & 39.0 & 43.4 \\
\hline
\end{tabular}

Source: Statistics South Africa (Stat SA). (2015). Quarterly Labour Force Survey - Quarter3. Statistics South Africa. Retrieved September 17, 2015, from http://www.statssa.gov.za

Note: 'Skilled' includes manager, professional and technician occupations; 'Semi-skilled' includes clerk, sales and services, skilled agriculture, craft and related trade and plant and machine operator occupations; 'Low-skilled' includes elementary and domestic worker occupations. 
African women and other women groups within the skilled, professional and managerial occupations are not representative of the demographics of SA. This gap becomes more prominent in an era where, to a certain extent, black African women pose more or less similar offerings in terms of education, knowledge, skills and capabilities, as women of other race groups, but still remain the most disadvantaged. This underrepresentation and slow progression of black African women in skilled, professional and managerial occupations support the literature in indicating that they are the most disadvantaged group among women in SA (Forger et al., 2001; Ministry for Welfare \& Population Development, 1998).

\section{Research design Research approach}

This study was qualitative, whereby in-depth, semistructured interviews were utilised in examining the influence of ML and PL on the career progression of black African women who are part of DCCs at an SOC, in middle management and leadership occupations. A qualitative design enriched the context of the study in comprehending real-life social experiences that black African women encounter in their daily working lives. The qualitative approach allows little or no disruption and manipulation of their existing working social life cohesion (Holiday, 2007; Holloway \& Wheeler, 2010).

\section{Research strategy}

An interpretivist theoretical approach was adopted in the study. The ontological stance of the researcher in the study was that there is no one realism. Based on the researcher's view, reality is subjective, socially accumulated and founded on the insights and experiences of the researcher and the participants (Creswell, 2007; Crotty, 1998). The epistemology was that of a naturalistic inquiry (Lincoln \& Cuba, 1985). According to Blumer (1969, pp. 46-48), 'a naturalistic inquiry refers to a special form of inquiry that respects the natural integrity of the empirical problem under study'. In the appreciation of this natural reliability, the problem must be deliberated in its normal enduring atmosphere, in the absence of any possible predetermined elements to it (Blumer, 1969).

\section{Research method}

\section{Research setting}

The study was conducted at an SOC in SA, as SOCs are considered to be one of the primary custodians in promoting employment equity in the best interest of the country's transformation policies. This SOC operates within the research and development and energy sectors. Its primary activities include research and development, engineering and manufacturing.

\section{Entrée and establishing researcher roles}

A researcher normally gains admission to an organisational setting by obtaining the consent of the persons in charge.
Permission to conduct the study at this SOC was granted by the Group Executive: Corporate Services. The researcher's role in this study was primarily that of an insider researcher; with consideration that the researcher is male, not yet married, not part of a DCC and not yet a father. This to a certain extent enhanced the researcher's lack of bias. The role was furthermore limited to that of a Human Resource (HR) business partner aspiring to add value and novel knowledge to the field of study (Schurink, 2005).

\section{Population and sampling}

The population of the study comprised black African women and black African men, who work at the SOC in middle and leadership occupations and who are part of a DCC. The sample consisted of 20 participants. Non-random convenience purposive sampling was utilised. The selection of the participants in qualitative studies largely emanates from the target population of the research setting, which materialises in a convenience purposive sample of individuals. These individuals would have had exposure to some of the problem statement elements (Ryan, Coughlin \& Cronin, 2007). As a result, their insights would greatly contribute towards the achievement of the study's objectives (Quick \& Hall, 2015).

The sample comprised 10 black African women and 10 black African men - whereby all 20 participants were permanent black African employees of the SOC, who had functional backgrounds in finance, human resources, science and engineering, research and development, training and development and corporate business management. Furthermore, the primary participants were black African women within the various levels of the organisational hierarchy, with a majority of them in middle management and leadership positions. Middle-level to leadership management-level positions were selected as they are the roles that are being researched. These positions are being studied as they are deemed to be career phases, which are both demanding and arduous in terms of leadership and achievement.

Furthermore, the sample selection criterion was that the black African women and black African men participating in the study must be married and part of a DCC and also have a minimum of one child in their individual family unit. Participants who had a minimum of one child offered an opportunity to examine the complexity involved in balancing domestic and employment roles as well as how ML and PL are utilised. This also highlighted the intricacy that transpires within the fundamentals of child-caring responsibilities.

\section{Data collection methods}

Semi-structured, in-depth, face-to-face interviews were utilised as the primary data collection mechanism for this study. In-depth interviewing, also called 'conversational interviewing' is a common technique utilised by qualitative researchers (Schurink, 1998). According to Schurink (1998), 
in-depth interviewing entails one or more face-to-face dialogues between an interviewer and an interviewee.

\section{Recording of data}

When recording data during qualitative research, researchers must pledge to keep their data physically well organised, develop a plan about how they foresee doing it and ensure that they adhere to their scheme or plan. Researchers must also create a back-up system. It is important to keep hard copies of all recorded data in a manual filing system, to ensure that valuable data are not lost in case of any unforeseen circumstances. Many different types of documents are used by researchers to enrich their data, and these need to be stored safely (Bogdan \& Biklen, 1992).

In this study, all the interviews were recorded by means of a digital dictaphone, accompanied by representative field notes. The researcher transcribed the data from the interviews to enhance confidentiality and anonymity of the participants (Nath, 2000). These measures ensured meticulousness in reflecting the participants' actual words, tone of voice and any other substantial information, which aided in understanding and analysing the responses of the participants. All the data were digitally stored on a laptop and backed up on two external hard drives for safeguarding (Schurink, 2004).

\section{Data analysis}

Thematic analysis was utilised to analyse the interview dialogues in the data analysis of this research. Thematic analysis can be stated to be a qualitative statistical methodology of factor analysis or exploration gathering, dually aiming to define a complex data set in relation to a number of scopes or groupings (Barker \& Pistrang, 2012). This entailed methodically classifying and consolidating understandings into patterns of meaning (themes) from the data.

Furthermore, the purpose of utilising thematic analysis was to realise and make sense of shared significances and experiences (Braun \& Clarke, 2012). It is mostly used to analyse interview data, whereby the researcher analyses the material inductively. Themes are derived from the data, rather than being established beforehand (Barker \& Pistrang, 2012).

\section{Soundness of the study}

The soundness of the study was determined by its credibility, transparency and transferability. Credibility can be established by whether the data dialogued with the participants relates to the conclusions of the research inquiry (Esterberg, 2002). Transferability is the capability to use a similar research method and process in other but similar circumstances and obtain comparable outcomes (Barker \& Pistrang, 2012).

Elliott, Fischer and Rennie (1999); Mays and Pope (2000) provide the below recommendations regarding trustworthiness, which were followed in the study:
1. Foundation (providing some of the raw data upon basing findings);

2. Transparency (revealing own preferences and prospects);

3. Consistency (themes correspond with data outline); and

4. Credibility checks (engaging other sources). (Barker \& Pistrang, 2012, n.p.)

In the quest to attain sound validity and credibility in qualitative research, a researcher's insider involvement has to be proclaimed throughout a qualitative study, irrespective of the picture this may depict (Miles \& Huberman, 1994). The involvement of the researcher has been clarified in this study.

In the endeavour to enrich credibility, comprehensive details pertaining to data gathering, analysis and interpretation of a study should be provided. Beck (2009), Patton (2014) and Shenton (2004) indicate that this practice accords replication of the research enhancing transparency, credibility and soundness of a study, highlighting the undesirable or different themes that materialised throughout the research project. In this study, field notes, taped dialogue recordings, original interview questionnaires, data and analyses were some of the key measures in supporting and apprehending the soundness of the study.

\section{Ethical considerations}

The researcher adhered to research ethics throughout this study. The primary objective and value of ethics is striving to protect the dignity, well-being, rights and interests of the participants involved in a research study at all times, regardless of any possible setbacks it may convey to a study (Quick \& Hall, 2015). Firstly, the participants were informed of the objectives of the research as well as their right to voluntary participation. The researcher also signed a declaration of confidentiality with the participants regarding the information obtained during the interviews. Participants also signed consent forms for their participation in the research and with regard to the recording of the interviews. The overall findings of the study will be shared with those participants who have requested to be informed once the study is completed, as a measure of enhancing transparency in the study.

\section{Research findings}

The primary purpose of the study was to examine the influence of $\mathrm{ML}$ and $\mathrm{PL}$ on the career progression of black African women as part of DCCs at an SOC, in order to obtain more insight on the underrepresentation and slow progression of black African women in middle management and leadership roles. As a result, eight key themes, described below, were identified during the interview process.

\section{Theme 1: Commitment and motivation}

The initial theme that came about was that of commitment and motivation. Lack of commitment and motivation was a challenge or barrier, in that its absence within black African women represented a hindering element that led to a 
complacent focus in black African women's career aspirations, affecting and delaying any proactive efforts of a positive career progression.

The participant responses in the study supported the above discussion and interpretation, whereby black African women indicated that a lack of commitment and motivation towards their careers was a self-imposed challenge. In comparison to men, the attitudes of women tend to be an important barrier in women's careers, if they are not being truly committed and motivated. Male participants in the study shared the same implication regarding black African women and women in general as not being committed and motivated to their careers, resulting in them not progressing as ideally as they had hoped. Based on the response summary of the participants, $70 \%$ of the black African women supported this theme and $80 \%$ of black African men were also in support of the theme, signifying its importance.

\section{Theme 2: Patriarchal dominance and power}

The second theme that came about in the study was patriarchal dominance and supremacy. This theme primarily indicated that apart from women being a great barrier in their career progression in terms of lacking commitment and motivation, men transpired to be an important barrier in their career progression, through a societal system that advantages and privileges men. Johnson (2005) describes patriarchy as a societal system that operates by essentially constructing privileges for men and concomitantly repressing women, which we all form a part of in one way or another.

Within the study, both male and female participants acknowledged patriarchal dominance and supremacy in their society as a barrier in the career progression of women in DCCs at the SOC, and more specifically for black African women. The participants' supporting responses indicated that the labour market is greatly male dominated and predominantly white male dominated, especially within the middle management to leadership positions.

\section{Theme 3: Internal family support}

The third theme that came about in the study was internal family support. As indicated in the literature, internal support is one of the most essential support elements for the career progression of black African women in DCCs, bearing in mind that black African women are still responsible for most of the household and childrearing burdens (Hall \& MacDermid, 2009; OECD, 2013). Besides the substantiating grounds for PL in terms of internal family support, $80 \%$ black African women participants indicated that emotional support was by far the most essential form of internal family support. Black African women also indicated that they admire emotional support more than any other benefits that can be derived from either PL or any other form or structure of internal family support. The participants further ascribed internal family support towards establishing and having a strong internal support structure at home.

\section{Theme 4: Organisational and managerial support}

Organisational and managerial support was the fourth theme that came about in the study. As depicted in the literature, April, Dreyer and Blass (2007) argued that, based on the situation-centred theory, employment and its environment can also become obstacles to the professional advancement of women.

The participants' responses supported the above interpretation in that they further acknowledged time off and availability as another deficient organisational support mechanism that also greatly influenced the career progression of black African women and women in general in DCCs at an SOC. This came about on a number of substantiating grounds, whereby $85 \%$ of the participants maintained that involuntary time off work and unavailability resulting from taking ML were the dominating and limiting factors in the career progression of black African women in DCCs.

\section{Theme 5: Culture and upbringing}

The fifth theme that came about in the study was culture and upbringing. Traditionally, men were expected to fulfil the role of sole earner in the household, while women were expected to assume economic dependency and the role of motherhood, with no aspiration for career acknowledgement and fulfilment (Bosch et al., 2012).

A certain number of black African women participants further portrayed a customary undesirable behaviour of perceiving the motherhood burden solely on themselves. Black African women seem to not realise that times and customary tradition have evolved and that men are equally accountable for actively taking part in fatherhood and household responsibilities (Harrington et al., 2012). As such, women tend to sell themselves short, by upholding certain customary practices that disadvantage them in the long run, even though times and culture have evolved to an extent that they are not compelled to do so.

\section{Theme 6: Training and development}

Training, development and mentoring came about as the sixth theme of the study. Both spouses in DCCs work vastly in experienced managerial, professional and leadership roles. As a result, it becomes quite apparent that education, training and even mentoring stand to be essential elements in both spouses gaining entry into these occupations and more importantly, in maintaining these roles and their work-life balance. In the absence of education, training and mentoring, they would most likely not have the necessary knowledge in being competent and excelling within their professional occupations (Hakim, 2002).

In the study, $65 \%$ of the participants supported and greatly acknowledged the impact of training, development as well as mentoring on the career progression of black African women in DCCs at an SOC. The sustenance came from both black 
African women and black African men participants underpinning the essentiality of this theme in the careers of black African women in DCCs. The participants' responses further specified the importance of career guidance at an early stage, as an important component in ensuring that black African women make the right career choices systematically and early within their career journeys. None of the black African women participants indicated having been mentored in any way thus far in their career journey, except for receiving some form of support from a manager.

\section{Theme 7: Socio-economic support}

The seventh theme that came about in the study was socioeconomic support. The absence of a fundamental socioeconomic support system that solemnly prioritises the participation and advancement of black African women in the labour market is considered a barrier to the career progression of black African woman. Within the study, 55\% of the participants' responses supported the above argument, whereby there was vast acknowledgement of black African women being the most undermined and underrepresented group of women in the labour market. The participants' responses further indicated a need for legislated PL. They also argued that although legislative bodies had the authority of implementing such legislated PL, they were not prioritising it on their agenda.

\section{Theme 8: Fairly progressed but not ideal careers for black African women}

The last and eighth theme that came about in the study was 'fairly progressed but not ideal' careers for black African women. This theme supported and reinforced all the previous themes generated and identified in the study, portraying a comprehensive overall story about the research data. All the identified themes in the study comprehended this unified and overarching theme of fairly progressed but not ideal careers for black African women. As a result, 80\% of black African women participants indicated that their careers had progressed fairly, but acknowledged that they were not in their ideal career phase. Of the black African men participants, $60 \%$ also acknowledged that their spouses' careers had progressed, but not ideally as they had hoped. Only 20\% of black African men admitted to their spouses' careers having progressed well, attributing such success to the support they had provided throughout their spouses' career.

\section{Discussion}

The primary aim of the study was to examine how taking ML and PL influences the career progression of black African women as part of DCCs at an SOC. The main and key finding of this study was that it was established that taking ML and PL had a direct and indirect influence on the career progression of black African women in DCCs at this SOC, in middle management and leadership occupations. Of the participants, $90 \%$ agreed that taking ML has a negative influence on the career progression of black African women in DCCs at the SOC, in middle management and leadership occupations. There were a number of direct and indirect influencing reasons for this influence, but the most predominant reasons emanated as a result of taking ML and $\mathrm{PL}$, and their underlying components, as indicated below.

Of the black African women participants, $80 \%$ indicated that their careers had progressed fairly, but acknowledged that they were not at their ideal career phase because of taking ML and other family-related commitments. Furthermore, $85 \%$ of the participants confirmed involuntary time off work and productiveness as principal influencing barriers of taking ML in the career progression of black African women in DCCs at the SOC, leading to other undesirable consequences, which can further impede on the career progression of black African women, such as unproductiveness, unreliability and stunted growth opportunities.

Of the black African men participants, $60 \%$ acknowledged that their spouses' careers had progressed, but not as ideally as they had hoped because of taking ML and other familyrelated commitments. Only $20 \%$ of black African men admitted to their spouses' careers having progressed well, attributing success to the support they had provided throughout their spouses' careers. Of the participants, including both black African women and black African men, 95\% agreed that taking PL has a positive influence on the career progression of black African women in DCCs at an SOC.

\section{Practical implications}

The low representation of black African women in DCCs at the SOC in middle management and leadership occupations depicts the influence that taking ML can have on their career progression. Current talent management and recruitment and selection policies engaged by management require to be reviewed in contributing positively to the career progression of black African women.

\section{Limitations to the study}

The most dominant limitations was that the study was only limited to one specific SOC, and therefore, does not represent the current status of other SOCs within the SA labour market. The private sector and other spheres of the government sector were not included as part of the research setting, omitting an untapped school of knowledge within the research topic. The sample of the study was limited to black African women and black African men within DCCs at this SOC, possibly leaving some untapped experiences of other black African women and women in general within their career progression journey. Furthermore, there was limited literature about African DCCs in general and about the relationship between ML and PL and the career progression of black African women in particular.

\section{Recommendations for future research}

Future research could be carried out on the same topic covering a broader sample of black African women and 
across the entire SA labour market in order to confirm the findings and durability of the current study. Furthermore, a quantitative approach covering a larger population could be adopted. Extended research could also look into other challenges and barriers, besides taking ML and PL, which play a role in the career progression of black African women within the SA labour market, specifically within the private sector or within SOCs.

\section{Conclusion}

The study established that there are direct and indirect influences that taking ML and PL have on the career progression of black African women at an SOC, in middle management and leadership occupations. In acknowledgement of this influence, the literature determined that in their quest for career progression, a majority of black African women still occupy unskilled occupations, highlighting their struggle in progressing into middle management and leadership occupations (QLFS, Q3, 2015). This highlighted the challenges of black African women especially those in DCCs, in their attempts to achieve their ideal career progression goals and objectives. The study further indicated that legislation still fails black African women, resulting in discrimination and stereotypes that still persist and remain a prevalent barrier. However, the study ascended two unfamiliar barriers; firstly that some black African women lack dedication to their careers and secondly, that their male counterparts are afforded privileges and advantages as a result of patriarchal dominance in the society, which further suppresses women in their career growth.

\section{Acknowledgements Competing interests}

The authors declare that they have no financial or personal relationships which may have inappropriately influenced them in writing this article.

\section{Authors' contributions}

The study was conducted by L.L.M. as part of his Masters in Human Resource Management research project in 2016. M.H.R.B. was L.L.M.'s supervisor and edited the work for publication. R.M.J. was L.L.M.'s co-supervisor and also assisted in editing the work for publication.

\section{References}

April, K., Dreyer, S., \& Blass, E. (2007). Gender impediments to the SA executive boardroom. SA Journal of Labour Relations, 31(2), 51-67.

Atkinson, C., \& Hall, L. (2009). The role of gender in varying forms of flexible working. Gender, Work \& Organization, 16(6), 650-666. https://doi.org/10.1111/j.1468-0432. 2009.00456.x

Barker, C., \& Pistrang, N. (2012). Varieties of qualitative research: A pragmatic approach to selecting methods. In H. Cooper (Ed.), APA handbook of research methods in psychology: Research designs (Vol. 2., pp. 5-18). Los Angeles, CA: Sage.

Beck, C.T. (2009). Critiquing qualitative research. AORN Journal, 9O(4), 543-554. https://doi.org/10.1016/j.aorn.2008.12.023

Bentley, K. (2004). Women's human rights and the feminisation of poverty in South Africa. Review of African Political Economy, 31(100), 247-261. https://doi. org/10.1080/0305624042000262275
Blumer, H. (1969). Symbolic interactionism: Perspective and method. Englewood Cliffs, NJ: Prentice Hall.

Bogdan, R.C., \& Biklen, S.K. (1992). Qualitative research for education: An introduction to theory and methods. 2nd ed. Boston, MA: Allyn \& Bacon.

Bosch, A., De Bruin, G.P., De Bruin, K., \& Kgaladi, B. (2012). Life role salience among black African dual-career couples in the South African context. The International Journal of Human Resources Management, 23(14), 2835-2853. https://doi.org/ 10.1080/09585192.2012.671506

Braun, V., \& Clarke, V. (2012). Thematic analysis. In H. Cooper (Ed.), APA handbook of research methods in psychology. Research designs, 2, (pp. 57-70). Los Angeles, CA: Sage.

Creswell, J. (2007). Qualitative inquiry and research design: Choosing among five approaches. London: Sage.

Crotty, M. (1998). The foundations of social research: Meaning and perspective in the research process. London: Sage.

Davidson, M. (1997). The black and ethnic minority women manager cracking the concrete ceiling. London: Paul Chapman.

De Vries, L. (1991). A study of the extent of discrimination against women in the workplace and the problems they encounter in the developing of an integrated management team. MBA Sociology. Stellenbosch: University of Stellenbosch.

Elliott, R., Fischer, C.T., \& Rennie, D.L. (1999). Evolving guidelines for publication of qualitative research studies in psychology and related fields. British Journal of Clinical Psychology, 38, 215-229. https://doi.org/10.1348/014466599162782

Esterberg, K.G. (2002). Qualitative methods in social research. Boston, MA: McGrawHill.

Evans. P.M. (2007). Comparative perspectives on changes to Canada's paid parental leave: Implications for class and gender. International Journal of Social Welfare, 16, 119-128. https://doi.org/10.1111/j.1468-2397.2006.00450.x

Flood, T., Hoosain, M., \& Primo, N. (1997). Beyond inequalities: Women in South Africa. Cape Town: Southern African Research and Documentation Centre.

Floro, M.S., \& Komatsu, H. (2011). Gender and work in South Africa: What can time use data reveal? Feminist Economics, 2(1), 1-37. https://doi.org/10.1080/135457 01.2011 .622722

Forger, H., Dimant, T., Corrigan, T., Mophuthing, T., Spratt, J., Pienaar, D., et al. (2001). South Africa Survey 2000/01. Johannesburg: South African Institute of Race Relations.

Givati, Y., \& Troiano, U. (2012). Theory of mandated benefits and evidence from maternity leave policies. The Journal of Law and Economics, 55(2), 339-364. maternity leave policies. The Jour

Greenhaus, J.H., Callanan, G.A., \& Godshalk, V.M. (2010). Career management (4th ed.). New York: Sage.

Greenhaus, J.H., \& Powell, G. (2006). When work and family are allies: A theory of work-family enrichment. Academy of Management Review, 31, 72-92. https:// doi.org/10.5465/AMR.2006.19379625

Gurjao, S. (2006). Inclusivity: The changing role of women in the construction workforce. London: The Chartered Institute of Building (CIOB).

Haas, L. (2003). Parental leave and gender equality: Lessons from the European Union. Review of Policy Research, 20, 89-114. https://doi.org/10.1111/15411338.00006

Hakim, C. (2002). Lifestyle preferences as determinants of women's differentiated labor market careers. Work and Occupations, 29(4), 428-459. https://doi. org/10.1177/0730888402029004003

Hall, D.T. (2002). Careers in and out of organizations. Thousand Oaks, CA: Sage.

Hall, S., \& MacDermid, S. (2009). A typology of dual earner marriages based on work and family arrangements. Journal of Family and Economic, 30(3), 215-225. $\mathrm{https}: / /$ doi.org/10.1007/s10834-009-9156-9

Hardill, I. (2002), Gender, migration and the dual career household. International Studies of Women and Place series. London: Routledge.

Harrington, B., Van Deusen, F., \& Mazar, I. (2012). The new dad: Right at home Boston, MA: Boston College Centre for Work \& Family.

Hermann, K.M. (2016). Dual-career couples. In W.K. Killam, S. Degges-White, R.E. Michel, W.K. Killam, S. Degges-White \& R.E. Michel (Eds.), Career counseling interventions: Practice with diverse clients, (pp. 35-43). New York: Springer Publishing Co.

Holiday, A. (2007). Doing and writing qualitative research: Approaching qualitative research. London: Sage.

Holloway, I., \& Wheeler, S. (2010). Qualitative research in nursing and healthcare. West Sussex: Wiley-Blackwell.

Ilies, R., Keeney, J., \& Scott, B. A. (2011). Work-family interpersonal capitalization: Sharing positive work events at home. Organizational Behaviour and Human Decision Processes, 114, 115-126. Industry Statistics, Pretoria.

Johnson, A.G. (2005). The gender knot: Unraveling our patriarchal legacy. Philadelphia, PA: Temple University Press.

Karenga, T., \& Tembo, C. (2012). Kawaida womanism: African ways of being woman in the world. Western Journal of Black Studies, 36(1), 33-47.

Lincoln, Y.S., \& Cuba, E.G. (1985). Naturalistic enquiry. Beverly Hills, CA: Sage.

Mainiero, L.A., \& Sullivan, S.E. (2005). Kaleidoscope careers: An alternative explanation for the 'opt-out' revolution. Academy of Management Executive, 19, 106-123. https://doi.org/10.5465/AME.2005.15841962 
Mays, N., \& Pope, C. (2000). Assessing quality in qualitative research. British Medical Journal, 320, 50-52. https://doi.org/10.1136/bmj.320.7226.50

Miles, M.B., \& Huberman, M. (1994). Qualitative data analysis: An expanded sourcebook. London: Sage.

Mokomane, Z. (2009). Work-family conflict and gender equality in South Africa. Unpublished paper presented at the 26 IUSSP International Population Conference, Held in Marrakech, Morocco, 27 September-02 October.

Moore, E. (2013). Transmission and change in South African motherhood: Black mothers in three-generational Cape Town families. Journal of Southern African Studies, 39(1), 151-170. https://doi.org/10.1080/03057070.2013.764713

Morrell, R., \& Richter, L. (2006). Men and fatherhood on South Africa. Cape Town: HSRC Press.

Moss, P. (2012). International review of leave policies and related research 2012 Retrieved n.d., from http://www.leavenetwork.org/fileadmin/Leavenetwork/ Annual_reviews/2012

Mumma, J. (2001). Relocation issues in today's workforce. Employment Relations Today, 28(1), 55-65. https://doi.org/10.1002/ert.1005.abs

Nath, D. (2000). Gently shattering the glass ceiling: Experiences of Indian women managers. Women in Management Review, 15(1), 44-52. https://doi.org/ $10.1108 / 09649420010310191$

OECD. (1995). Long-term leave for parents in OECD countries. In OECD, Employment Outlook, (pp. 171-202). Paris: OECD.

OECD. (2013). Employment outlook 2013. Paris: OECD Publishing.

Patton, M.Q. (2014). Qualitative evaluation and research methods. Saint Paul, MN Sage.

Pesonen, A. (2015). Encouraging work-family balance to correct gender imbalance: A comparison of the family and medical leave act and the Iceland Act on maternity/paternity and parental leave. Journal of International Studies, 15(1) 157-196.

Quick, J., \& Hall. S. (2015). Spotlight on research. Part Two: Qualitative Research, 25(7-8), 125-133.

Rajadhyaksha, U., \& Bhatnagar, D. (2000). Life role salience: A study of dual-career couples in the Indian context. Human Relations, 53(4), 491-493. https://doi. org/10.1177/0018726700534002

Ryan, F., Coughlin, M., \& Cronin, P. (2007). Step by step guide to critiquing research Part 2: Qualitative research. British Journal of Nursing, 16(12), 738-744. https:// doi.org/10.12968/bjon.2007.16.12.23726

Sadie, J. (2015). Gender policy and legislation during the first 20 years of democracy. Strategic review for Southern Africa, 36(2), 111-125.

Salmera-Aro, K., Nurmi, J.E., Saisto, T., \& Halmesmäki, E. (2000). Women's and men's personal goals during the transition to parenthood. Journal of Family Psychology, 14, 171-186. https://doi.org/10.1037/0893-3200.14.2.171

Santho, S. (1995). The elimination of gender inequality in the public service with specific reference to the Free State provincial administration. MPA Economic and Administrative Science. Bloemfontein: University of the Orange Free State.
Schurink, E.M. (1998). Data analysis in qualitative research. In A. de Vos (Ed.), Research at grass roots: A primer for the caring professions. Pretoria: Van Schaik Publishers.

Schurink, W.J. (2004). Qualitative research introducing key features of an interpretative approach to social science research: Lecture Eleven B, Grounded Theory. Doctora Programme in Leadership in Performance and Change (pp. 1-23). Johannesburg: University of Johannesburg.

Schurink, W.J. (2005). Qualitative research design: Part 1 lecture notes to $D$ - and $M$ students from the leadership in performance and change programme. Johannesburg: University of Johannesburg,

Sewpaul, V. (1994). The position of black women in South African society: A feminist perspective. Social Work, 30(4), 346-354.

Shenton, A.K. (2004). Strategies for ensuring trustworthiness in qualitative research projects. Education for Information, 22, 63-75. https://doi.org/10.3233/EFI-2004 22201

Smit, R. (2006). Family related policies in Southern African countries: Are working parents reaping any benefits? Journal of Comparative Family Studies, 1(1), 15-36.

South Africa. (1995). Labour Relations Act, Act 66 of 1995. Pretoria: Government Printer.

South Africa. (1996). Constitution of the Republic of South Africa, Act 108 of 1996 Pretoria: Government Printer.

South Africa. (1997). Basic Conditions of Employment Act, Act 75 of 1997. Pretoria: Government Printer.

South Africa. (1998a). Employment Equity Act, Act 55 of 1998. Pretoria: Government Printer.

South Africa. (1998b). Labour Relations Amendment Act, Act 127 of 1998. Pretoria: Government Printer.

South Africa. (1998c). Skills Development Act, Act 97 of 1998. Pretoria: Government Printer.

South Africa. (1999). Public Finance Management Act, 1. Government Gazette No. 33059. Pretoria: Government Printer.

South Africa. (2001). Commission on Gender Equality Act, Act 39 of 1996. Pretoria: Government Printer.

South Africa. Ministry for Welfare and Population Development. (1998). White Paper on Population Policy. Retrieved June 21, 2015, from http://www.gov.za/ whitepaper

Statistics South Africa (Stat SA). (2015). Quarterly Labour Force Survey - Quarter3. Statistics South Africa. Retrieved September 17, 2015, from http://www.statssa. gov.za

Talley-Ross, N. (1995). Jagged edges: Black professional women in white male worlds. New York: Peter Lang.

Tshoaedi, M. (2012). Women in the forefront of workplace struggles in South Africa: From invisibility to mobilization. Labour, Capital and Society, 45(2), 58-83.

Wall, K. (2014). Fathers on leave alone: Does it make a difference to their lives. Fathering. Men's Studies Press, 12(2), 196-210.

Wheatly, D. (2013). Location, vocation, location? Spatial entrapment among women in dual-career households. Gender, Work \& Organization, 20(6), 720-736. 